\title{
Comparison of Rhenium and Iodine as Contrast Agents in X-Ray Imaging
}

\author{
José Carlos De La Vega ${ }^{D},{ }^{1}$ Pedro Luis Esquinas $\left(\mathbb{D},{ }^{2}\right.$ Jovan Kaur Gill, ${ }^{1}$ Selin Jessa, ${ }^{1}$ \\ Bradford Gill, ${ }^{3}$ Yogesh Thakur $\mathbb{D}^{4,5}$ Katayoun Saatchi ${ }^{4}{ }^{1},{ }^{1}$ and Urs O. Häfeli $\mathbb{D}^{1}$ \\ ${ }^{1}$ Faculty of Pharmaceutical Sciences, University of British Columbia, Vancouver, British Columbia, Canada \\ ${ }^{2}$ Medical Imaging Research Group, Department of Radiology, University of British Columbia, Vancouver, \\ British Columbia, Canada \\ ${ }^{3}$ Medical Physics Department, BC Cancer, Vancouver, British Columbia, Canada \\ ${ }^{4}$ Department of Radiology, University of British Columbia, Vancouver, British Columbia, Canada \\ ${ }^{5}$ Medical Imaging, Vancouver Coastal Health, Vancouver, British Columbia, Canada
}

Correspondence should be addressed to Katayoun Saatchi; kathy.saatchi@ubc.ca and Urs O. Häfeli; urs.hafeli@ubc.ca

Received 28 July 2021; Revised 22 September 2021; Accepted 1 October 2021; Published 1 November 2021

Academic Editor: Alexey P. Kostikov

\begin{abstract}
Copyright ( 92021 José Carlos De La Vega et al. This is an open access article distributed under the Creative Commons Attribution License, which permits unrestricted use, distribution, and reproduction in any medium, provided the original work is properly cited.
\end{abstract}

\begin{abstract}
Purpose. The majority of X-ray contrast agents (XCA) are made with iodine, but iodine-based XCA (I-XCA) exhibit low contrast in high $\mathrm{kVp}$ X-rays due to iodine's low atomic number $(Z=53)$ and $\mathrm{K}$-edge $(33.1 \mathrm{keV})$. While rhenium is a transition metal with a high atomic number $(Z=75)$ and $\mathrm{K}$-edge $(71.7 \mathrm{keV})$, the utilization of rhenium-based XCA (Re-XCA) in X-ray imaging techniques has not been studied in depth. Our study had two objectives: (1) to compare both the image quality and the absorbed dose of I- and Re-XCA and (2) to prepare and image a rhenium-doped scaffold. Procedures. I- and Re-XCA were prepared and imaged from 50 to $120 \mathrm{kVp}$ by Micro-computed tomography ( $\mu \mathrm{CT}$ ) and digital radiography and from 120 to $220 \mathrm{kVp}$ by planar $\mathrm{X}$-ray imaging. The scans were repeated using 0.1 to $1.6 \mathrm{~mm}$ thick copper filters to harden the X-ray beam. A rhenium-doped scaffold was prepared via electrospinning, used to coat catheters, and imaged at $90 \mathrm{kVp}$ by $\mu \mathrm{CT}$. Results. I-XCA have a greater contrast-to-noise ratio (CNR) at 50 and $80 \mathrm{kVp}$, but Re-XCA have a greater CNR at $>120 \mathrm{kVp}$. The difference in CNR is increased as the thickness of the copper filters is increased. For instance, the percent CNR improvement of rhenium over iodine is $14.2 \%$ with a $0.6 \mathrm{~mm}$ thick copper filter, but it is $59.1 \%$ with a $1.6 \mathrm{~mm}$ thick copper filter, as shown at $120 \mathrm{kVp}$ by $\mu \mathrm{CT}$. Upon coating them with a rhenium-doped scaffold, the catheters became radiopaque. Conclusions. Using Monte Carlo simulations, we showed that it is possible to reduce the absorbed dose of high $\mathrm{kVp} \mathrm{X}$-rays while allowing the acquisition of high-quality images. Furthermore, radiopaque catheters have the potential of enhancing the contrast during catheterizations and helping physicians to place catheters inside patients more rapidly and precisely.
\end{abstract}

\section{Introduction}

$\mathrm{X}$-ray imaging techniques require the administration of $\mathrm{X}$-ray contrast agents (XCA) to enhance the contrast between fluid, tissue, and/or anatomical structures. The majority of XCA are solutions of iodinated compounds, which are administered to patients via intravenous or intra-arterial injections before radiographic examinations [1]. The evolution in the structure of iodine-based XCA (I-XCA) moved from inorganic iodine (specifically sodium iodide, or $\mathrm{NaI}$ ) to organic mono-, di-, and tri-iodinated compounds; from lipophilic to hydrophilic compounds; from ionic to nonionic compounds; and more recently, from monomers to dimers. These modifications aimed to increase the iodine content and reduce the incidence of adverse effects [2].

I-XCA are rapidly excreted by the kidneys, thus requiring repeated large doses to achieve good contrast. The dose of iodine is typically small, $\sim 3 \mathrm{~g}$ in lumbar, thoracic, cervical, and columnar radiographic examinations $[3,4]$, but it could be as high as $\sim 30 \mathrm{~g}$ in coronary computed 
tomography (CT) angiography [5] and $100 \mathrm{~g}$ in angiography and angioplasty [6]. I-XCA have been linked to several adverse effects with an estimated incidence between $1 \%$ and $12 \%$ [7]. These adverse effects may range from mild reactions, such as itching and emesis, to life-threatening emergencies, such as hypersensitivity reactions, thyroid dysfunction, anaphylaxis, and nephropathy [8-10].

At the energies and atomic numbers under consideration, the attenuation of X-rays is dependent upon the atomic number raised to the third power [11]. Due to its low atomic number $(Z=53)$, iodine attenuates high $\mathrm{kVp} X$-rays $(>80 \mathrm{kVp})$ to a lesser degree than other high- $Z$ elements. For this reason, images typically exhibit low contrast and high noise [12,13]. While most scans are performed between 24 (e.g., mammography) and $140 \mathrm{kVp}$ (e.g., chest CT) [14], the suboptimal attenuation of iodine may be problematic in scans of average-sized and large patients, which are typically performed at 100 to $140 \mathrm{kVp}$ [15-17].

The development of iodine-free XCA has garnered a lot of interest to overcome these limitations. Most research has focused on replacing iodine with elements with a greater atomic number, such as gold $(Z=79)$ [18-22], bismuth $(Z=83)[23,24]$, and tantalum $(Z=73)[25,26]$. Among all these elements, gold has played the leading role in the development of iodine-free XCA, in the form of nanoparticles (NP). One of the advantages of gold NP (AuNP) is that they have been investigated for many years for other biomedical applications (e.g., photoacoustic imaging, photothermal ablation, and DNA detection) [27]. AuNP have been shown to exhibit good biotolerability (Median Lethal Dose, or $\mathrm{LD}_{50}=3.2 \mathrm{~g}$ of gold per $\mathrm{kg}$ ) $[21,28,29]$. Many researchers have examined the X-ray attenuation of AuNP through both phantom and animal studies. These studies have shown that AuNP have a higher X-ray attenuation [18-21] and a longer circulation half-life [30-32] than I-XCA.

Since gold is more expensive than iodine, other high- $\mathrm{Z}$ elements, like bismuth and tantalum, have also been studied. Bismuth has the advantage of decomposing in vivo to small and renally clearable $\mathrm{Bi}$ (III) species as a result of its tendency to oxidize and hydrolyze in water (i.e., it does not accumulate in the body) [33]. A few examples of bismuth NPs (i.e., BiNPs) under investigation are ultra-high payload BiNPs [34], bismuth glyconanoparticles (BiGNP) [35], and bismuth(III) sulfide $\left(\mathrm{Bi}_{2} \mathrm{~S}_{3}\right) \mathrm{NP}[23,24]$. Tantalum is also of interest as an XCA, particularly when it reacts with oxygen to form tantalum pentoxide (or $\mathrm{Ta}_{2} \mathrm{O}_{5}$ ) due to its biocompatibility, chemical stability, and high solubility in water. The use of tantalum pentoxide as an XCA was reported many years ago in bronchography, after delivery as a powder aerosol via the trachea [36]. Current efforts revolve around the production of NP comprised of a core made of tantalum pentoxide $[25,26]$.

The utilization of rhenium in X-ray imaging has only been reported in a few manuscripts by Krasilnikova et al. [37-40] despite its high atomic number $(Z=75)$ and low cost compared with gold (1,300 USD per kg of rhenium vs. 44,800 USD per $\mathrm{kg}$ of gold) [41]. Rhenium is a chemically versatile element with rich coordination chemistry. While it can exist in oxidation states from -1 to +7 [42], rhenium complexes are thermodynamically more stable in their higher oxidation states and they oxidize in vivo to perrhenate $\left(\mathrm{ReO}_{4}-\right)$. This transformation occurs because perrhenate features rhenium in the oxidation state of +7 , which is rhenium's preferred oxidation state $[42,43]$. This is of importance for clinical applications because the pharmacokinetics of perrhenate is well-understood: it is taken up by the thyroid, retained there with a biological half-life of $12 \mathrm{~h}$, and finally excreted via the kidneys [44-47]. Furthermore, perrhenate has been shown to have a half-maximal effective concentration $\left(\mathrm{EC}_{50}\right)$ of $1 \mathrm{mM}$ or higher, which is an indication of its low toxicity $[48,49]$.

The objective of this study was to compare the attenuation of Re- and I-XCA over a wide range of experimental conditions. We evaluated the image quality, which was calculated experimentally using preclinical and clinical equipment, and the absorbed dose, which was estimated through Monte Carlo simulations for clinical equipment. Specifically, the samples were imaged from 50 to $120 \mathrm{kVp}$ by micro-CT $(\mu \mathrm{CT})$ (preclinical equipment) and digital radiography (clinical equipment) and from 120 to $220 \mathrm{kVp}$ by planar X-ray imaging (preclinical equipment).

A specific application of the use of rhenium in X-ray imaging was studied by coating catheters with a rheniumdoped scaffold. Large doses of I-XCA are administered to patients during catheterizations because the majority of catheters are radiolucent. The incorporation of a rheniumdoped scaffold onto the surface of the catheters has the potential of making them radiopaque, thus providing a visual guide for physicians during catheterizations and potentially reducing the use of I-XCA.

\section{Material and Methods}

2.1. Investigation of the Image Quality. $\mathrm{Re}$ - and I-XCA with a final concentration of rhenium and iodine of 50,100, and $200 \mathrm{mM}$ were prepared by diluting ammonium perrhenate (Sigma-Aldrich; Oakville, Ontario, Canada) and iohexol (Omnipaque $^{\mathrm{TM}}$, $300 \mathrm{mg}$ of I per mL, GE Healthcare; Little Chalfont, Buckinghamshire, United Kingdom), which is a clinically used I-XCA, in water.

2.1.1. Micro-Computed Tomography. Six microcentrifuge tubes with $1 \mathrm{~mL}$ of the Re- and I-XCA were prepared. Two additional microcentrifuge tubes with water and air were prepared as controls. The microcentrifuge tubes were placed in a cylindrical phantom (mCTP 610, Shelley Medical Imaging Technologies; London, Ontario, Canada), where they were arranged in a concentric circle. The phantom was made of three poly(methyl methacrylate) (PMMA, or Plexiglas ${ }^{\circledR}$ ) plates contained in a polycarbonate housing. The thickness of each plate was $1.3 \mathrm{~cm}$, thus providing a total filtration of $3.9 \mathrm{~cm}$ of PMMA [50].

The XCA were imaged using a preclinical $\mu \mathrm{CT}$ scanner (eXplore CT120, TriFoil Imaging; Chatsworth, California, United States) with an inherent filtration of $1 \mathrm{~mm}$ of aluminum and $0.15 \mathrm{~mm}$ of beryllium. As additional filtration, a $0.6 \mathrm{~mm}$ thick copper filter was placed between the phantom 
and the X-ray tube. The settings were set at $50 \mathrm{kVp}(80 \mathrm{mAs}$ and $125 \mathrm{~ms}), 80 \mathrm{kVp}(60 \mathrm{~mA}$ and $125 \mathrm{~ms})$, and $120 \mathrm{kVp}$ (40 $\mathrm{mA}$ and $63 \mathrm{~ms}$ ).

To evaluate the effect of additional filtration on the image quality, the $120 \mathrm{kVp}$ scan was repeated with 1.2 and $1.6 \mathrm{~mm}$ thick copper filters between the phantom and the X-ray tube. SpekCalc, a computational tool available in MATLAB ${ }^{\mathrm{TM}}$ $[51,52]$, was utilized to predict the X-ray spectra for all the exposures performed at $120 \mathrm{kVp}$.

The settings of all the scans are summarized in Table 1.

The acquisition consisted of 1,440 projections per scan. The scanner was operated in a step-and-shoot mode. To cool the anode during acquisition, a step delay of $3 \mathrm{~s}$ was used for the 50 and $80 \mathrm{kVp}$ scans, while a step delay of $7 \mathrm{~s}$ was used for the $120 \mathrm{kVp}$ scans.

MicroView (Parallax Innovations; Ilderton, Canada) was used to reconstruct the data as three-dimensional (3D) images with a matrix size of $1455 \times 1455$ and a spatial resolution of $50 \mu \mathrm{m}$. For each $3 \mathrm{D}$ image, this software was also utilized to measure the mean voxel intensity of each sample in a cylindrical volume of interest (VOI) with a diameter and height of 50 pixels. The contrast-to-noise ratio (CNR) of each sample was calculated relative to water using the following equation:

$$
\mathrm{CNR}=\frac{\bar{\iota}_{i}-\bar{\iota}_{\mathrm{H}_{2} \mathrm{O}}}{\sigma_{\mathrm{H}_{2} \mathrm{O}}},
$$

where $\bar{l}$ represents the mean voxel intensity, $\sigma$ represents the standard deviation of the mean voxel intensity, and $i$ represents the sample of interest [53]. The analysis was conducted in triplicate.

2.1.2. Planar X-Ray Imaging. The XCA with a concentration of rhenium and iodine of $200 \mathrm{mM}$ were imaged between 120 and $220 \mathrm{kVp}$ using the Small Animal Radiation Research Platform (SARRP) (Xstrahl, Walsall Wood, UK). The XCA were imaged in microcuvettes with $1 \mathrm{~mL}$ each. Two microcuvettes with water and air were included in all the scans as controls. The XCA were arranged in a straight line $30 \mathrm{~cm}$ away from the X-ray tube. A $0.1 \mathrm{~mm}$ thick copper filter was used as additional filtration. The settings of all the scans are summarized in Table 2.

To minimize the heel effect, which causes discrepancies in the intensity of the pixels from the left to the right side of the images as a result of the reduction in the intensity of the $\mathrm{X}$-ray beam along the cathode-anode axis in the X-ray tube, the position of the XCA was changed between scans as indicated in Figure 1.

Using ImageJ [54], images acquired at the same X-ray tube potential but using different configurations (i.e., "original", as in Figure 1(a), and "inverted", as in Figure 1(b)) were averaged pixel by pixel. All the images had a matrix with a size of $1024 \times 1024$. The samples were kept as close to each other as possible during the scans to further compensate for the nonuniform intensity of the X-ray beam.

The same software was also utilized to measure the mean pixel intensity of each XCA in a square-shaped region-ofinterest (ROI) with sides made of 50 pixels. These values were used to calculate the CNRs. The analysis was performed in triplicate.

2.1.3. Digital Radiography. The XCA with a concentration of rhenium and iodine of $200 \mathrm{mM}$ were imaged at 50, 81, and $121 \mathrm{kVp}$ using a clinical X-ray tube camera (Multix X-ray, Siemens AG, Munich, Germany) with a digital radiography retrofit (DRX; New York, United States). A sample holder with six $200 \mu \mathrm{L}$ wells was fabricated with PMMA to image the solutions (Figure 2). For all the scans, a total of $175 \mu \mathrm{L}$ of each solution were pipetted into the wells. As in all previous experiments, water and air were used as controls.

The distance between the XCA and the X-ray tube focal spot was set to $102 \mathrm{~cm}$. As per the manufacturer's specifications, the instrument's inherent filtration was $3.9 \mathrm{~mm}$ of aluminum. The exposures were carried out with varying thicknesses of additional filtration, from 0 to $1.5 \mathrm{~mm}$ of copper. In all the scans, a RAYSAFE Xi platinum (Fluke, United States) was placed on top of the samples as shown in Figure 2 to measure the incident air kerma. The settings of the scans are summarized in Table 3.

All the images had a matrix with a size of $2520 \times 3032$ and were processed on the digital system with the "Pattern" algorithm (a flat field algorithm). ImageJ was used to measure the mean pixel intensities of the samples in circular ROIs with a diameter of 5 pixels. These values were then used to calculate the CNRs. The analysis was performed in triplicate.

2.2. Investigation of the Absorbed Dose. Using as a reference the experimental setup described in Section 2.1.3, the depth absorbed dose profile and the average absorbed dose in a Solid Water ${ }^{\circledR}$ phantom (Best, Nashville, Tennessee, United States) were estimated utilizing Monte Carlo simulations implemented with Geant4 Application for Tomographic Emission (GATE) [55]. For simplicity, the phantom was simulated as a cuboid with length, width, and height of 30 , 30 , and $20 \mathrm{~cm}$, respectively. The calculations were performed considering an inherent filtration of $1 \mathrm{~mm}$ of aluminum and $0.15 \mathrm{~mm}$ of beryllium. The distance between the phantom and the X-ray tube was set to $100 \mathrm{~cm}$.

The simulations were conducted at 50,80 , and $120 \mathrm{kVp}$ in the absence of sources of additional filtration. Then, they were repeated at $120 \mathrm{kVp}$ in the presence of $0.1,0.3,0.5,1$, and $1.5 \mathrm{~mm}$ thick copper filters. The X-ray spectra were modeled using experimental data acquired with the preclinical $\mu \mathrm{CT}$ scanner (eXplore CT120, TriFoil Imaging; Chatsworth, USA) described in Section 2.1.1. For each exposure, the current was adjusted to simulate $8.5 \times 10^{5}$ photons transmitted out of the phantom (i.e., reaching the detector). This value was defined based on the number of photons in the transmitted X-ray beam at $120 \mathrm{kVp}$ with $0.5 \mathrm{~mm}$ of copper as additional filtration, also determined with Monte Carlo calculations. The detector was considered to have an efficiency of $100 \%$. All the simulations were carried out assuming a static and divergent $\mathrm{X}$-ray beam with a field of view (FOV) of $20 \mathrm{~cm}$ in diameter on the phantom's 
TABLe 1: Settings for micro-computed tomography.

\begin{tabular}{lccccc}
\hline $\begin{array}{l}\text { Scan } \\
\text { ID }\end{array}$ & $\begin{array}{c}\text { X-ray tube potential } \\
(\mathrm{kVp})\end{array}$ & $\begin{array}{c}\text { Amount of additional filtration } \\
(\mathrm{mm} \text { of Cu})\end{array}$ & $\begin{array}{c}\text { Current } \\
(\mathrm{mA})\end{array}$ & $\begin{array}{c}\text { Exposure time } \\
(\mathrm{ms})\end{array}$ & $\begin{array}{c}\text { Current-exposure time product } \\
(\mathrm{mAs})\end{array}$ \\
\hline X01 & 50 & 0.6 & 80 & 125 & 10 \\
X02 & 80 & 0.6 & 60 & 125 & 7.5 \\
X03 & 120 & 0.6 & 40 & 63 & 2.5 \\
X04 & 120 & 1.2 & 40 & 63 & 2.5 \\
X05 & 120 & 1.6 & 40 & 125 & 5 \\
\hline
\end{tabular}

The XCA were imaged at 50, 80 , and $120 \mathrm{kVp}$ using a preclinical $\mu \mathrm{CT}$ scanner. The current and the exposure time were selected to avoid saturation of the detector. The spatial resolution of the images after reconstruction was $50 \mu \mathrm{m}$.

TABle 2: Settings for planar X-ray imaging.

\begin{tabular}{lccc}
\hline Scan ID & X-ray tube potential $(\mathrm{kVp})$ & Amount of additional filtration $(\mathrm{mm}$ of $\mathrm{Cu})$ & $\mathrm{Current}(\mathrm{mA})$ \\
\hline X06 & 120 & 0.1 & 0.5 \\
X07 & 140 & 0.1 & 0.1 \\
X08 & 160 & 0.1 & 0.5 \\
X09 & 180 & 0.1 & 0.5 \\
X10 & 200 & 0.1 & 0.5 \\
X11 & 220 &
\end{tabular}

The XCA were imaged between 120 and $220 \mathrm{kVp}$ using the SAARP.
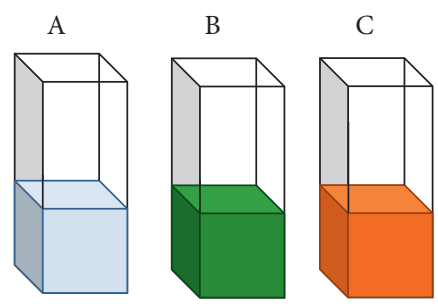

(a)
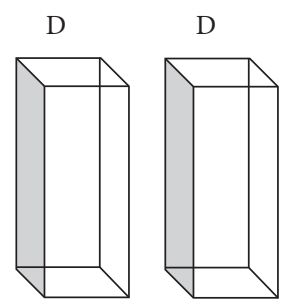
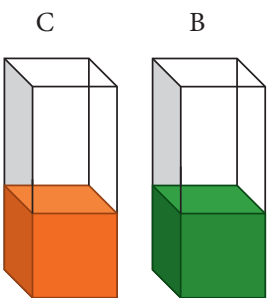

(b)

FIGURE 1: Setup for planar X-ray imaging. The Re- and I-XCA were imaged initially as indicated in (a) ("original” configuration). Then, they were rearranged as indicated in (b) ("inverted" configuration) and imaged again. The images from both configurations at each X-ray tube potential were averaged to generate a single image, which was then utilized to calculate the CNRs. The image shows (A) water, (B) Re-XCA, (C) I-XCA, and (D) air.

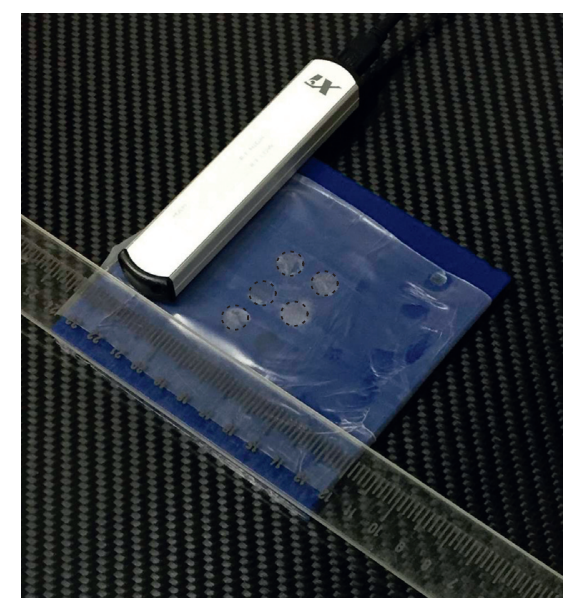

FIGUre 2: Sample holder. The sample holder, made of PMMA, was able to accommodate up to six XCA with a volume of $175 \mu \mathrm{L}$. There was a distance of $0.5 \mathrm{~cm}$ between wells. The circumferences of the wells were delineated with dashed lines to make them more noticeable. The position of the ionization chamber was kept the same in all the exposures. surface. Figure 3 depicts a schematic of the geometry of the simulation.

2.3. Preparation of Rhenium-Doped Electrospun Scaffolds. A rhenium-doped scaffold made of polycaprolactone (PCL) was produced by electrospinning, a technique used to produce scaffolds constituted of nanofibers (NFs). A rhenium phosphinophenolate complex $\left[\operatorname{ReOCl}(\mathrm{MePO})_{2}\right]$ was synthetized [56] and dissolved at a concentration of $2 \% \mathrm{w} / \mathrm{v}$ in a mixture of chloroform and methanol (70/30\% v/v). Subsequently, $45 \mathrm{kDa}$ PCL (Sigma Aldrich, Oakville, Ontario, Canada) was added at a concentration of $20 \% \mathrm{w} / \mathrm{v}$ and $2.5 \mathrm{~mL}$ of the solution was electrospun in a $10 \mathrm{~mL}$ syringe with a $20 \mathrm{G}$ $1 / 2$ " blunt needle using an electrospinner (Kato Tech Co., Ltd.; Kyoto, Japan). The electrospinning distance was set to $20 \mathrm{~cm}$, the distance advancement rate to $0.07 \mathrm{~mm} \cdot \mathrm{min}^{-1}$, and the voltage to $25 \mathrm{kV}$. The system was maintained in a horizontal position. The collecting plate was wrapped in aluminum foil, which acted as conducting material, and it was rotated at a speed of $20 \mathrm{~cm} \mathrm{~min}^{-1}$. The rhenium-doped 
TABLE 3: Settings for digital radiography.

\begin{tabular}{|c|c|c|c|}
\hline Exposure ID & $\mathrm{X}$-ray tube potential $(\mathrm{kVp})$ & Amount of additional filtration $(\mathrm{mm}$ of $\mathrm{Cu})$ & Current (mA) \\
\hline $\mathrm{X} 12$ & 50 & 0 & 1.25 \\
\hline $\mathrm{X} 13$ & 50 & 0.1 & 2.5 \\
\hline $\mathrm{X} 14$ & 50 & 0.3 & 10 \\
\hline $\mathrm{X} 15$ & 50 & 0.5 & 36 \\
\hline $\mathrm{X} 16$ & 50 & 1 & 71 \\
\hline $\mathrm{X} 17$ & 50 & 1.5 & 71 \\
\hline $\mathrm{X} 18$ & 81 & 0 & 1.25 \\
\hline X19 & 81 & 0.1 & 1.6 \\
\hline $\mathrm{X} 20$ & 81 & 0.3 & 1.6 \\
\hline $\mathrm{X} 21$ & 81 & 0.5 & 2.2 \\
\hline $\mathrm{X} 22$ & 81 & 1 & 4 \\
\hline $\mathrm{X} 23$ & 81 & 1.5 & 4 \\
\hline $\mathrm{X} 24$ & 121 & 0 & 1.25 \\
\hline $\mathrm{X} 25$ & 121 & 0.1 & 1.25 \\
\hline $\mathrm{X} 26$ & 121 & 0.3 & 1.25 \\
\hline $\mathrm{X} 27$ & 121 & 0.5 & 1.25 \\
\hline $\mathrm{X} 28$ & 121 & 1 & 1.25 \\
\hline $\mathrm{X} 29$ & 121 & 1.5 & 1.25 \\
\hline
\end{tabular}

The Re- and I-XCA were imaged at 50, 81 , and $121 \mathrm{kVp}$ using a clinical X-ray camera. The current was chosen to avoid saturation of the detector.

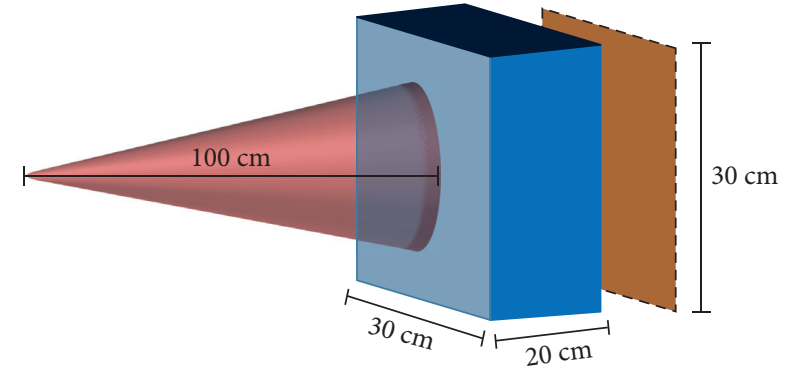

FIgure 3: Geometry of Monte Carlo simulation. The schematic shows the X-ray beam (red), the Solid Water ${ }^{\circledR}$ phantom (blue), and the detector (brown). A FOV of $20 \mathrm{~cm}$ at the surface of the phantom was chosen. All the simulations were conducted assuming a total of $8.5 \times 10^{5}$ photons in the transmitted X-ray beam.

scaffold was collected on a $3 \mathrm{~cm}$ strip for $\sim 4 \mathrm{~h}$. A rheniumfree scaffold (i.e., without the rhenium complex) was produced under the same experimental conditions.

To investigate their morphology at the nanoscale, $0.25 \mathrm{~cm}^{2}$ square-shaped samples of the scaffolds were imaged by scanning electron microscopy (SEM; SU3500, Hitachi; Chiyoda, Japan). The samples were mounted onto a specimen stub covered with an electrically conductive carbon-based adhesive disc. They were then sputter-coated with an $8 \mathrm{~nm}$ layer of iridium using a modular high vacuum coating system (EM MED020, Leica, Wetzlar, Germany) under reduced pressure $(<5 \mathrm{~Pa})$. The images were acquired at $15 \mathrm{kV}$ with a magnification of $10,000 \mathrm{x}$.

A rectangular-shaped sample of the rhenium-doped scaffold was incorporated onto the surface of a short section of a vascular catheter made of polyethylene $(P E-50, I D=0.05 \mathrm{~cm}$ and $\mathrm{OD}=0.10 \mathrm{~cm}$, where ID and $\mathrm{OD}$ stand for inner and outer diameters, respectively; Intramedic ${ }^{\mathrm{TM}}$, Becton Dickinson). The sample had a length of $1.5 \mathrm{~cm}$ and a width of approximately $2 \mathrm{~mm}$, but it was actually constituted of eight layers, which facilitated handling and processing. The catheter was wrapped with the scaffold carefully but tightly. The scaffold/catheter system was then completely covered with aluminum foil and placed directly on the surface of a hot plate equipped with a temperature probe. The temperature was initially set to $55^{\circ} \mathrm{C}$ but it was slowly increased in $1^{\circ} \mathrm{C}$ increments until the scaffold melted, which occurred at $59^{\circ} \mathrm{C}$. The catheter was removed from the hot plate and allowed to cool down. The same procedure was utilized to coat another section of the same catheter with the rhenium-free scaffold.

Following the same steps, the balloon in a percutaneous transluminal coronary angioplasty (PTCA) dilatation catheter (Long Cobra 40 ${ }^{\mathrm{TM}}$, SciMed Life Systems, Inc.) was coated with the rhenium-doped and the rhenium-free scaffolds. The scaffolds were applied directly on top of the balloon, without air (i.e., not expanded).

The coated sections of the catheters were cut and placed inside microcentrifuge tubes for imaging by $\mu \mathrm{CT}$ using a high-resolution specimen scanner $(\mu \mathrm{CT} 100$, SCANCO Medical, Brüttisellen, Switzerland). The samples were imaged at $90 \mathrm{kVp}(200 \mu \mathrm{A}$ and $550 \mathrm{~ms})$. According to the manufacturer's specifications, the only source of filtration in the scanner was the X-ray window, made of $0.15 \mathrm{~mm}$ of beryllium. The acquisition consisted of 1,000 projections. Using MicroView (Parallax Innovations, Ilderton, Canada), the data was reconstructed as a $3 \mathrm{D}$ image with a matrix size of $2048 \times 2048$ and a spatial resolution of $5 \mu \mathrm{m}$.

\section{Results and Discussion}

\subsection{Investigation of the Image Quality}

3.1.1. Micro-Computed Tomography. A positive correlation was found between the CNR and the concentration of rhenium and iodine at each X-ray tube potential. That is, there is an improvement in contrast as the concentration of rhenium and iodine is increased from 50 to $200 \mathrm{mM}$. These findings, which are consistent with other studies [57-59], are depicted graphically in Figure 4(a) for the exposures 


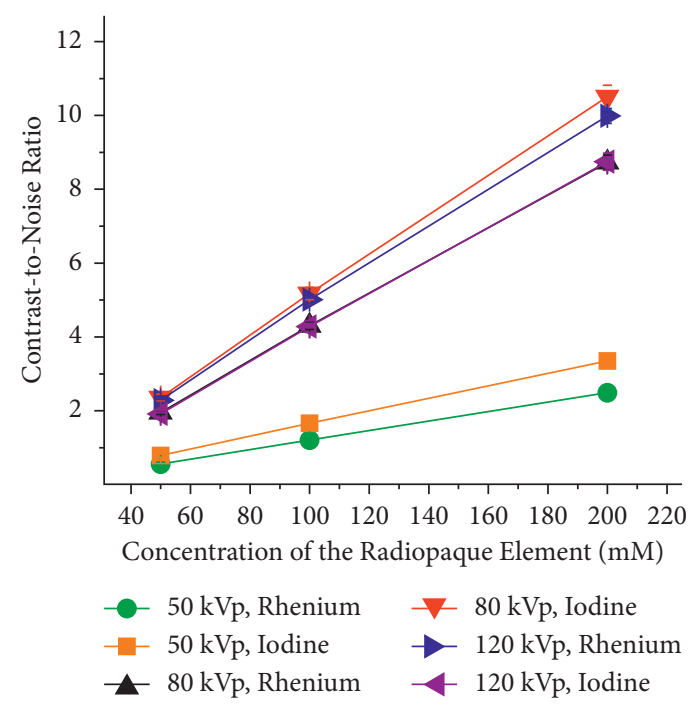

(a)

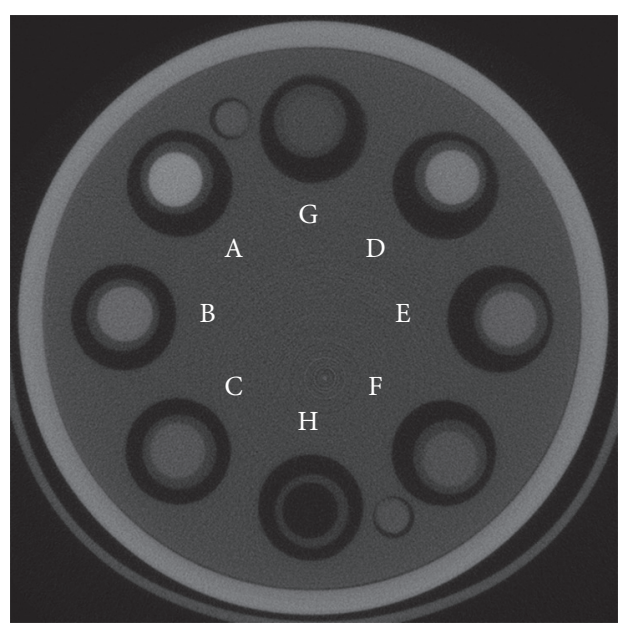

(b)

FIGURE 4: Evaluation of the contrast-to-noise ratio in micro-computed tomography. (a) The graph shows the relationship between the CNR and the concentration of the radiopaque element in the XCA. The scans were carried out at $50 \mathrm{kVp}(10 \mathrm{mAs}), 80 \mathrm{kVp}(7.5 \mathrm{mAs})$, and $120 \mathrm{kVp}$ $(2.5 \mathrm{mAs})$ with a $0.6 \mathrm{~mm}$ thick copper filter, that is, exposures X01, X02, and X03, respectively (see Table 1). (b) Axial image acquired at $50 \mathrm{kVp}$ showing the following XCA: I-XCA ((A) $200 \mathrm{mM}$, (B) $100 \mathrm{mM}$, and (C) $50 \mathrm{mM}$ ), Re-XCA ((D) $200 \mathrm{mM}$, (E) $100 \mathrm{mM}$, and (F) $50 \mathrm{mM}$ ), and controls ((G) water and (H) air). Attenuation: (A) 1,746 HU, (B) $863 \mathrm{HU},(\mathrm{C}) 403 \mathrm{HU},(\mathrm{D}) 1,297 \mathrm{HU},(\mathrm{E}) 622 \mathrm{HU},(\mathrm{F}) 285 \mathrm{HU}$, (G) -9.5 , and $(\mathrm{H})-994 \mathrm{HU}$. The scan corresponds to X01 (see Table 1). The XCA were imaged by $\mu \mathrm{CT}$.

performed with a $0.6 \mathrm{~mm}$ thick copper filter. A representative axial image of the samples acquired at $50 \mathrm{kVp}$ is depicted in Figure 4(b). The attenuation, reported in HU, was calculated using the Hounsfield scale, which is a linear transformation of the linear X-ray attenuation coefficient that takes as a reference the attenuation of air and water [60].

The quantitative VOI-based analysis showed that the CNRs of rhenium and iodine are dependent upon the X-ray tube potential. This is exemplified in Figure 5 for the scans conducted with a $0.6 \mathrm{~mm}$ thick copper filter. The I-XCA has a greater CNR than the Re-XCA at 50 and $80 \mathrm{kVp}$, but the Re-XCA has a higher CNR at $120 \mathrm{kVp}$.

Figure 6 shows the effect of the addition of further filters of copper on the CNRs of the XCA at $120 \mathrm{kVp}$. The difference in CNR is increased as the thickness of the copper filter is increased from 0.6 to $1.6 \mathrm{~mm}$. For instance, the percent CNR improvement of rhenium over iodine is $14.2 \%$ when the thickness of the copper filter is $0.6 \mathrm{~mm}$, but it is $59.1 \%$ when the thickness of the copper filter is $1.6 \mathrm{~mm}$. Figure 7 depicts axial images acquired in all of these scans.

These results suggest that rhenium exhibits a $\mathrm{kVp}$-dependent superiority in CNR (thus, in attenuation) over iodine. The greater attenuation of rhenium at $120 \mathrm{kVp}$ is associated with the differential K-edge of rhenium and iodine. Based on data published by the National Institute of Standards and Technology (NIST), [61] the mass attenuation coefficient (i.e., the linear attenuation coefficient divided by the density, expressed in units of $\mathrm{cm}^{2} \mathrm{~g}^{-1}$ ) of iodine is higher than rhenium between $33.1 \mathrm{keV}$ (iodine's K-edge) and $71.7 \mathrm{keV}$ (rhenium's K-edge). However, the mass attenuation coefficient of rhenium is consistently higher than iodine above $71.7 \mathrm{keV}$; Figure 8 depicts the $120 \mathrm{kVp} \mathrm{X}$-ray spectra

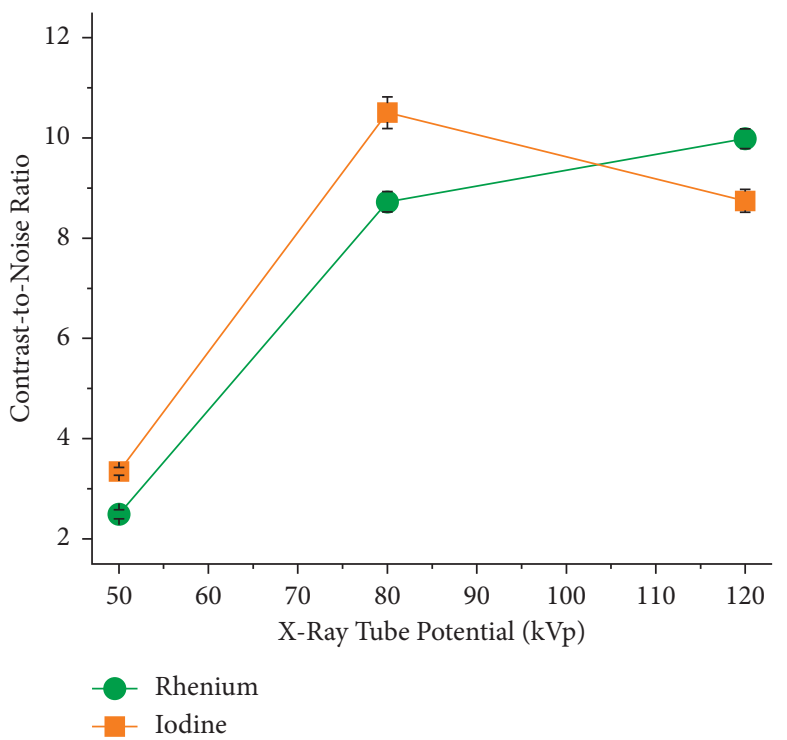

FIGURE 5: Effect of the X-ray tube potential on the contrast-to-noise ratio. The concentration of rhenium and iodine in the XCA was $200 \mathrm{mM}$. A $0.6 \mathrm{~mm}$ thick copper filter was used as additional filtration. The XCA were imaged by $\mu \mathrm{CT}$. Settings: $50 \mathrm{kVp}(10 \mathrm{mAs})$, $80 \mathrm{kVp}(5 \mathrm{mAs})$, and $120 \mathrm{kVp}(2.5 \mathrm{mAs})$, that is, exposures $\mathrm{X} 01$, $\mathrm{X} 02$, and X03, respectively (see Table 1).

simulated with SpekCalc, where it is observed that the X-ray beam produced in each scan was significantly hardened with the addition of copper filters. For instance, the mean energy of the $120 \mathrm{kVp}$ X-ray beam was increased from $39.8 \mathrm{keV}$ (without a copper filter) to 63.2, 67.8, and $69.5 \mathrm{keV}$ (with 0.6 , 1.2 , and $1.6 \mathrm{~mm}$ thick copper filters, respectively). This 


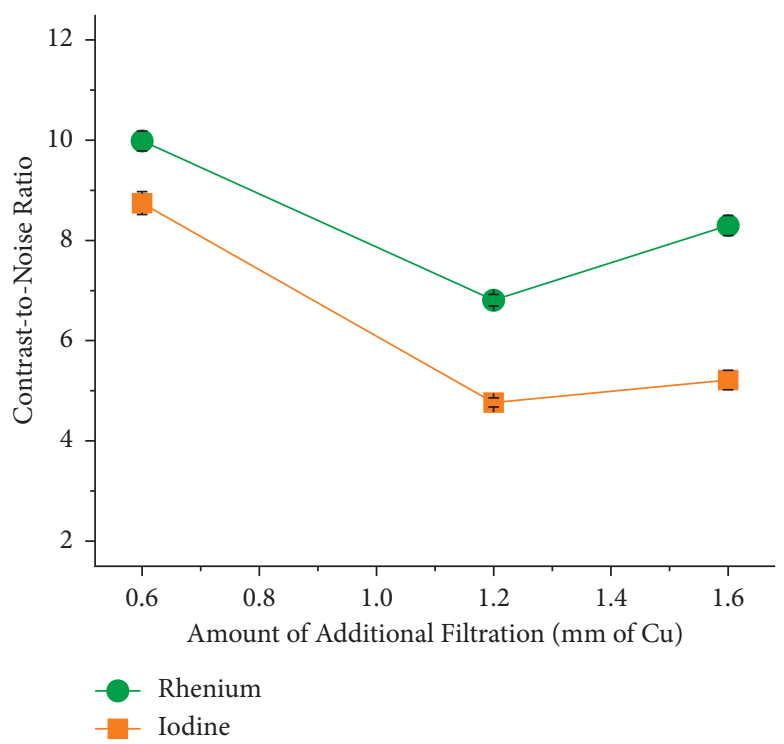

FIGURE 6: Effect of the amount of additional filtration on the contrast-to-noise ratio. The percent CNR improvement of rhenium over iodine is increased as the amount of additional filtration is increased. The concentration of rhenium and iodine in the XCA was $200 \mathrm{mM}$. The XCA were imaged by $\mu \mathrm{CT}$. All the scans were conducted at $120 \mathrm{kVp}$. They correspond to exposures X03, X04, and X05 (see Table 1).

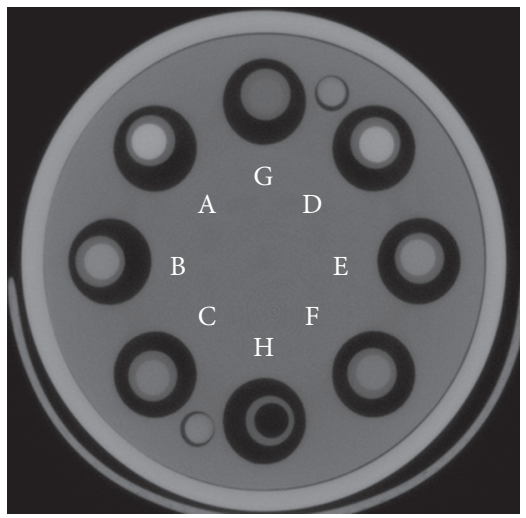

(a)

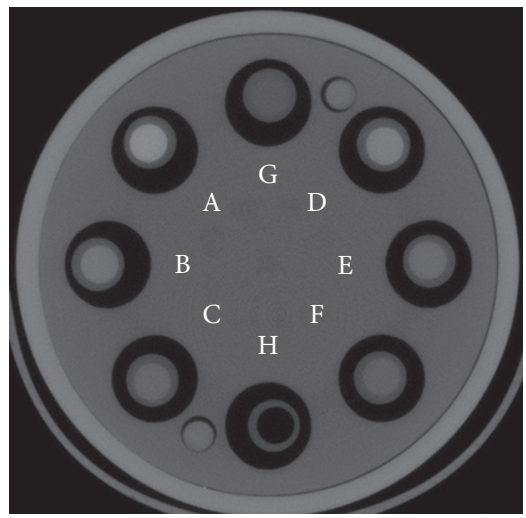

(b)

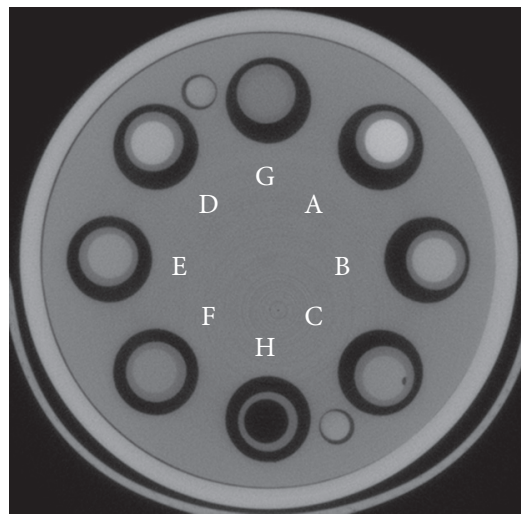

(c)

FIgURE 7: Micro-computed tomography imaging of rhenium and iodine. Representative axial images acquired at $120 \mathrm{kVp}$ by $\mu \mathrm{CT}$ with copper filters with the following thicknesses: (a) 0.6, (b) 1.2 , and (c) $1.6 \mathrm{~mm}$. The exposures correspond to X03, X04, and X05, respectively (see Table 1). The images depict the following XCA: Re-XCA ((A) $200 \mathrm{mM}$, (B) $100 \mathrm{mM}$, and (C) $50 \mathrm{mM}$ ), I-XCA ((D) $200 \mathrm{mM}$, (E) $100 \mathrm{mM}$, and (F) $50 \mathrm{mM}$ ), and controls ((G) water and (H) air). Attenuation: in (a), (A) $917 \mathrm{HU},(\mathrm{B}) 460 \mathrm{HU},(\mathrm{C}) 210 \mathrm{HU},(\mathrm{D}) 803 \mathrm{HU},(\mathrm{E}) 393 \mathrm{HU},(\mathrm{F})$ $176 \mathrm{HU},(\mathrm{G})$ 0, and (H) -998 HU. In (b), (A) $942 \mathrm{HU},(B) 473 \mathrm{HU},(\mathrm{C}) 218 \mathrm{HU},(\mathrm{D}) 661 \mathrm{HU}$, (E) $321 \mathrm{HU},(\mathrm{F}) 138 \mathrm{HU},(\mathrm{G}) 1$, and (H) -996 HU. In (c), (A) $971 \mathrm{HU},(B) 486 \mathrm{HU},(\mathrm{C}) 227 \mathrm{HU}$, (D) $610 \mathrm{HU}$, (E) $305 \mathrm{HU},(\mathrm{F}) 137 \mathrm{HU},(\mathrm{G}) 0$, and (H) -998 HU.

suggests that the main factor contributing to the increased CNR of rhenium at $120 \mathrm{kVp}$ is the removal of low $\mathrm{keV}$ photons, which are more likely to interact with iodine.

3.1.2. Planar X-Ray Imaging. The relationship between the $\mathrm{CNR}$ and the X-ray tube potential is depicted in Figure 9. The graph shows that the CNR of iodine at $220 \mathrm{kVp}$ is $26.4 \%$ greater than at $120 \mathrm{kVp}$. This moderate improvement in CNR is associated with the overall increase in photon count at $220 \mathrm{kVp}$. Rhenium, on the other hand, shows an increase in CNR of $39.0 \%$. The improvement in CNR of rhenium at $220 \mathrm{kVp}$ is associated with the increase in the proportion of photons with energy above rhenium's K-edge. Furthermore, it was found that the difference in CNR between rhenium and iodine is increased when the $\mathrm{X}$-ray tube potential is increased. For example, the percent CNR improvement of rhenium over iodine is $32.2 \%$ at $120 \mathrm{kVp}$, but it is $45.3 \%$ at $220 \mathrm{kVp}$.

3.1.3. Digital Radiography. The variation in CNR at 50, 81, and $121 \mathrm{kVp}$ as a function of the amount of additional filtration is graphically shown in Figure 10. The experiments conducted by $\mu \mathrm{CT}$ showed that iodine exhibits a greater $\mathrm{CNR}$ than rhenium at $50 \mathrm{kVp}$ (see Figure 5). Figure 10 shows 


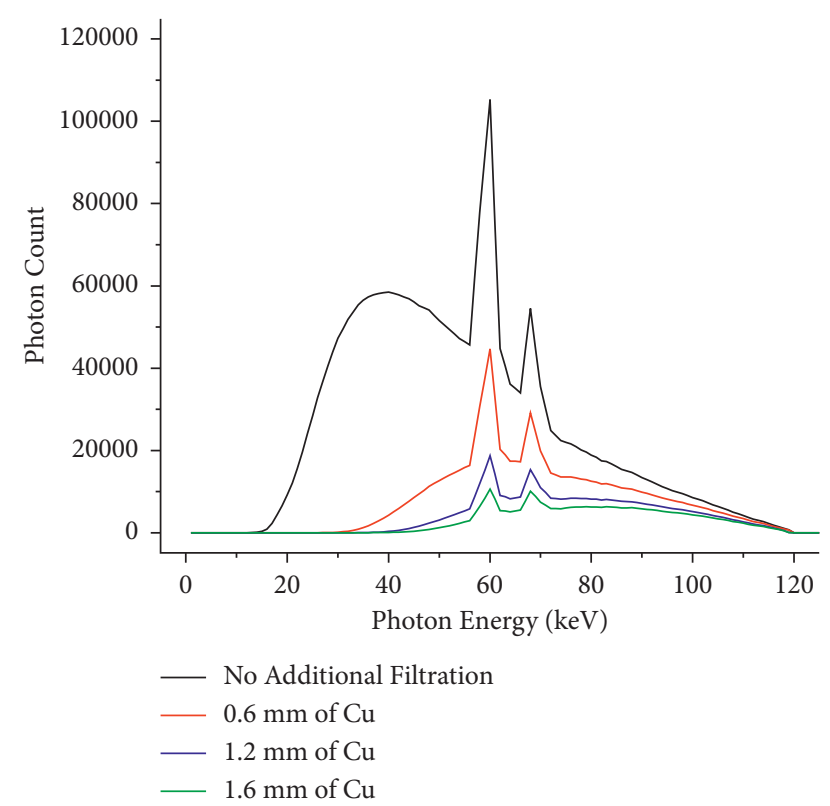

Figure 8: Effect of copper on the $120 \mathrm{kVp} \mathrm{X}$-ray spectra. The image shows the $120 \mathrm{kVp} \mathrm{X}$-ray spectra transmitted through copper filters with thicknesses up to $1.6 \mathrm{~mm}$. The mean energy of each X-ray spectra is $39.8 \mathrm{keV}$ when there is no additional filtration, $63.2 \mathrm{keV}$ with a $0.6 \mathrm{~mm}$ thick copper filter, $67.8 \mathrm{keV}$ with a $1.2 \mathrm{~mm}$ thick copper filter, and $69.5 \mathrm{keV}$ with a $1.6 \mathrm{~mm}$ thick copper filter. The Xray spectra were predicted using SpekCalc.

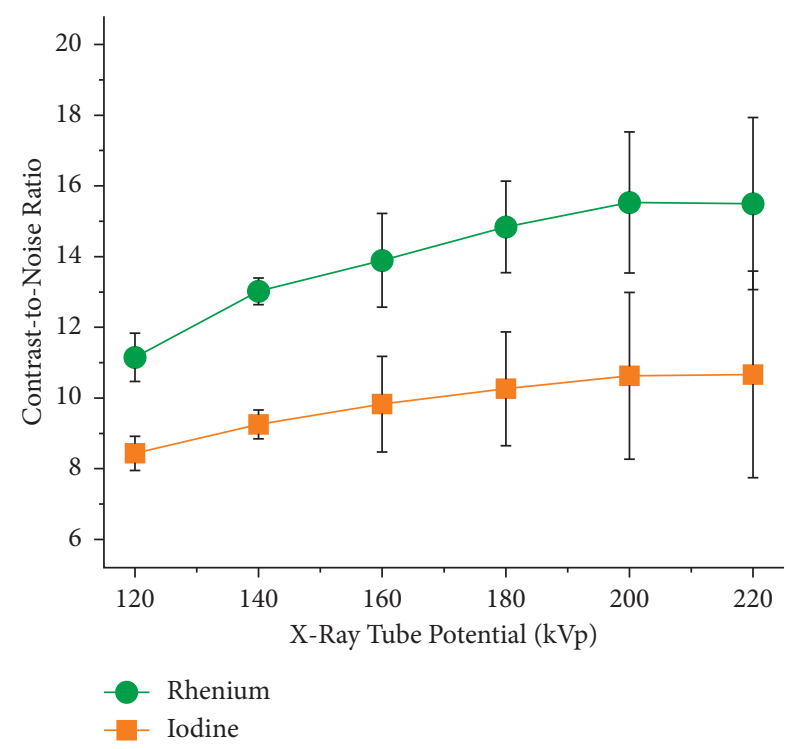

FIGURE 9: Effect of the X-ray tube potential on the contrast-to-noise ratio. The Re-XCA consistently displays a greater CNR than the I$\mathrm{XCA}$ from 120 to $220 \mathrm{kVp}$. The concentration of rhenium and iodine in the XCA was $200 \mathrm{mM}$. The XCA were imaged by planar $\mathrm{X}$-ray imaging using the SARRP. All the scans were carried out with a current of $50 \mu \mathrm{A}$ and $0.1 \mathrm{~mm}$ of copper as additional filtration, that is, exposures X06 to X11 (see Table 2).

that rhenium can exhibit a greater CNR than iodine at $50 \mathrm{kVp}$ depending on the amount of additional filtration. At $50 \mathrm{kVp}$, rhenium has a higher CNR than iodine in two cases:

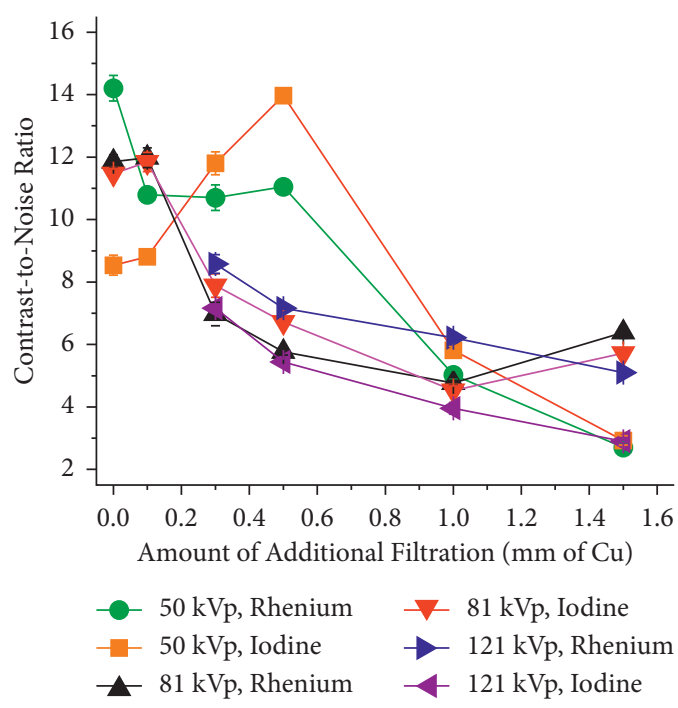

FIgURE 10: Evaluation of the contrast-to-noise ratio in digital radiography. The concentration of rhenium and iodine in the XCA was $200 \mathrm{mM}$. The XCA were imaged by digital radiography using a clinical X-ray camera (Multix X-ray, Siemens AG; Munich, Germany). The scans correspond to X12 to X23 and X26 to X29 (see Table 3). The images from exposures X24 and X25 were excluded from the analysis due to lack of contrast. As a consequence of the use of insufficient additional filtration in these two scans, the detector was saturated with photons when the current was $1.25 \mathrm{~mA}$, which is the lowest current that can be selected in the instrument.

(1) without any source of additional filtration (i.e., the only source of filtration is the instrument's inherent filtration, equivalent to $3.9 \mathrm{~mm}$ of aluminum) and (2) with a $0.1 \mathrm{~mm}$ thick copper filter. These differences in attenuation are caused by changes in the energy spectrum of the X-ray beam incident on the XCA.

Similar to the scans performed by $\mu \mathrm{CT}$ and planar X-ray imaging, rhenium consistently has a greater CNR than iodine at $121 \mathrm{kVp}$. While the CNRs of both samples are decreased as the thickness of the copper filters is increased, the difference in CNR between rhenium and iodine is increased. For example, the percent CNR improvement of rhenium over iodine is $19.8 \%$ in the presence of a $0.3 \mathrm{~mm}$ thick copper filter, but it is $75.9 \%$, almost four times higher, in the presence of a $1.5 \mathrm{~mm}$ thick copper filter.

3.2. Investigation of the Absorbed Dose. The incident air kerma and the mean energy of the X-ray beam, calculated from X-ray spectra predicted using SpekCalc, are summarized in Table 4.

To compare the differential attenuation of rhenium and iodine across all the scans, we calculated a rhenium-to-iodine X-ray attenuation ratio. We divided the mean pixel intensity of rhenium by the mean pixel intensity of iodine and divided this quotient by the incident air kerma of each scan. Figure 11 illustrates the relationship between the rhenium-to-iodine $\mathrm{X}$-ray attenuation ratio, determined experimentally, and the mean energy of the X-ray beam. As a reference, a theoretical rhenium-to-iodine mass X-ray attenuation coefficient ratio was also calculated and plotted in 
TABLE 4: Measurement of the incident air kerma and the mean energy of the X-ray beam.

\begin{tabular}{|c|c|c|c|c|}
\hline Scan ID & $\mathrm{X}$-ray tube potential $(\mathrm{kVp})$ & Amount of additional filtration $(\mathrm{mm}$ of $\mathrm{Cu})$ & Incident air kerma $(\mu \mathrm{Gy})$ & Mean energy $(\mathrm{keV})$ \\
\hline $\mathrm{X} 17$ & 50 & 0 & $14.9+0.1$ & 28.5 \\
\hline $\mathrm{X} 18$ & 50 & 0.1 & 10.5 & 36.2 \\
\hline $\mathrm{X} 19$ & 50 & 0.3 & 11.2 & 39.6 \\
\hline $\mathrm{X} 20$ & 50 & 0.5 & 15.4 & 41.4 \\
\hline $\mathrm{X} 21$ & 50 & 1 & 4.2 & 43.9 \\
\hline $\mathrm{X} 22$ & 50 & 1.5 & 1.3 & 45.1 \\
\hline $\mathrm{X} 23$ & 81 & 0 & $49.3+0.2$ & 43.1 \\
\hline $\mathrm{X} 24$ & 81 & 0.1 & $31.9+0.6$ & 48.1 \\
\hline $\mathrm{X} 25$ & 81 & 0.3 & $15.4+0.1$ & 53.4 \\
\hline $\mathrm{X} 26$ & 81 & 0.5 & 12.5 & 56.5 \\
\hline $\mathrm{X} 27$ & 81 & 1 & 9.3 & 61.0 \\
\hline $\mathrm{X} 28$ & 81 & 1.5 & $21.2+0.1$ & 63.7 \\
\hline $\mathrm{X} 29$ & 121 & 0 & $114.9+0.2$ & 53.9 \\
\hline $\mathrm{X} 30$ & 121 & 0.1 & $74.0+0.2$ & 59.7 \\
\hline $\mathrm{X} 31$ & 121 & 0.3 & $46.0+0.1$ & 65.9 \\
\hline X32 & 121 & 0.5 & $33.4+0.1$ & 69.8 \\
\hline X33 & 121 & 1 & $19.7+0.1$ & 76.1 \\
\hline X34 & 121 & 1.5 & $11.7+0.1$ & 80.5 \\
\hline
\end{tabular}

The incident air kerma is reported as the mean of three independent measurements. The standard deviation is zero in cases where it is not reported.

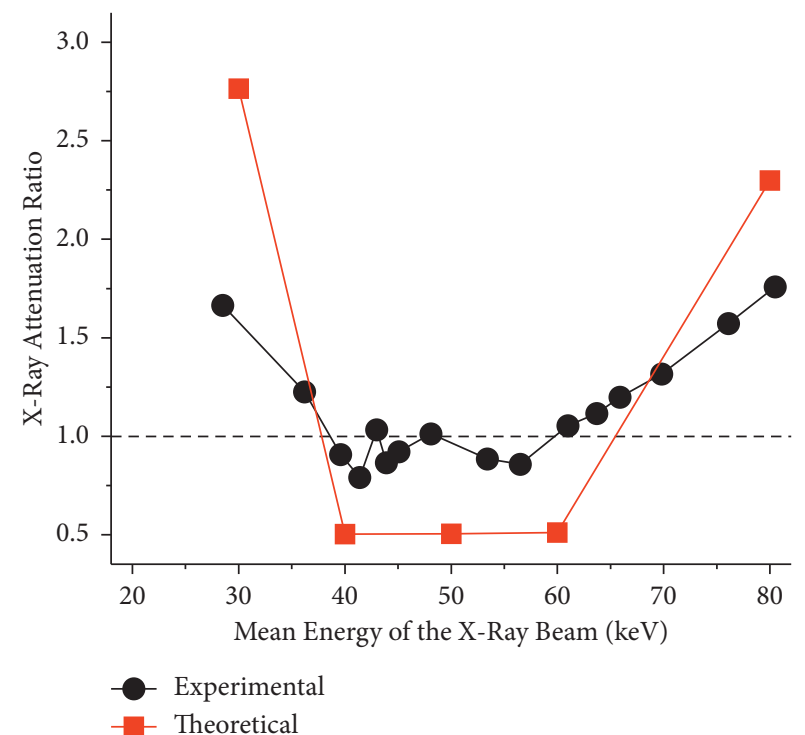

FIgURE 11: Rhenium-to-iodine X-ray attenuation ratio. The experimental curve was derived by dividing the mean pixel intensity of rhenium by the mean pixel intensity of iodine and dividing this value by the incident air kerma. The theoretical curve, on the other hand, was calculated from data reported by the NIST [61]. Basically, it represents the ratio of the mass X-ray attenuation coefficient of rhenium to the mass $\mathrm{X}$-ray attenuation of iodine.

Figure 11. Basically, when the rhenium-to-iodine X-ray attenuation ratio is above 1 , rhenium outperforms iodine (i.e., rhenium is expected to have a higher attenuation and CNR), but when it is below 1, iodine outperforms rhenium (i.e., iodine is expected to have a higher attenuation and CNR). The deviation between the experimental and the theoretical curves might be due to noise in the images and scattering from the surrounding media.

A higher incident air kerma is expected when a larger $\mathrm{X}$-ray tube potential is applied because photons with greater energy are produced. The incident air kerma, however, does not necessarily correlate with absorbed dose [62]. Using Monte Carlo, we assessed the differences in absorbed dose in 50,80 , and $120 \mathrm{kVp}$ scans, similar to the ones described above.

Figure 12(a) depicts the change in the average absorbed dose per slice (with a thickness of $1 \mathrm{~cm}$ ) as a function of the depth of the phantom for 50,80 , and $120 \mathrm{kVp}$ scans with no additional filtration. At $50 \mathrm{kVp}$, significantly more radiation dose is deposited in the phantom. The relative average absorbed dose was found to be five times larger at $50 \mathrm{kVp}$ than at $120 \mathrm{kVp}$. Also, while the difference is not as large, the relative average absorbed dose at $80 \mathrm{kVp}$ is almost double that at $120 \mathrm{kVp}$. These values are summarized in Table 5 . Figure 12(b) shows that the relative absorbed dose is significantly reduced at $120 \mathrm{kVp}$ when the amount of additional filtration is increased. For example, the relative average absorbed dose is reduced $37.6 \%$ after the addition of a $1.5 \mathrm{~mm}$ thick copper filter. The curves show that the highest deposition of radiation dose occurs within a couple of centimeters of the surface of the phantom.

3.3. Preparation of Rhenium-Doped Electrospun Scaffolds. SEM showed that both the rhenium-doped and the rhenium-free scaffolds were made of a smooth and continuous network of NFs (Figure 13).

Figures 14(a) and 14(c) show images of the two catheters after coating them with samples of the rhenium-doped and the rhenium-free scaffolds. Figures $14(\mathrm{~b})$ and 14(d) show representative $\mu \mathrm{CT}$ axial images of the catheters, where it is seen that the rhenium-doped polymer-based coating has higher contrast than the rhenium-free polymer-based coating.

No variation in the contrast was observed across the rhenium-doped polymer-based coating. This was demonstrated quantitatively by calculating the distribution of grey 


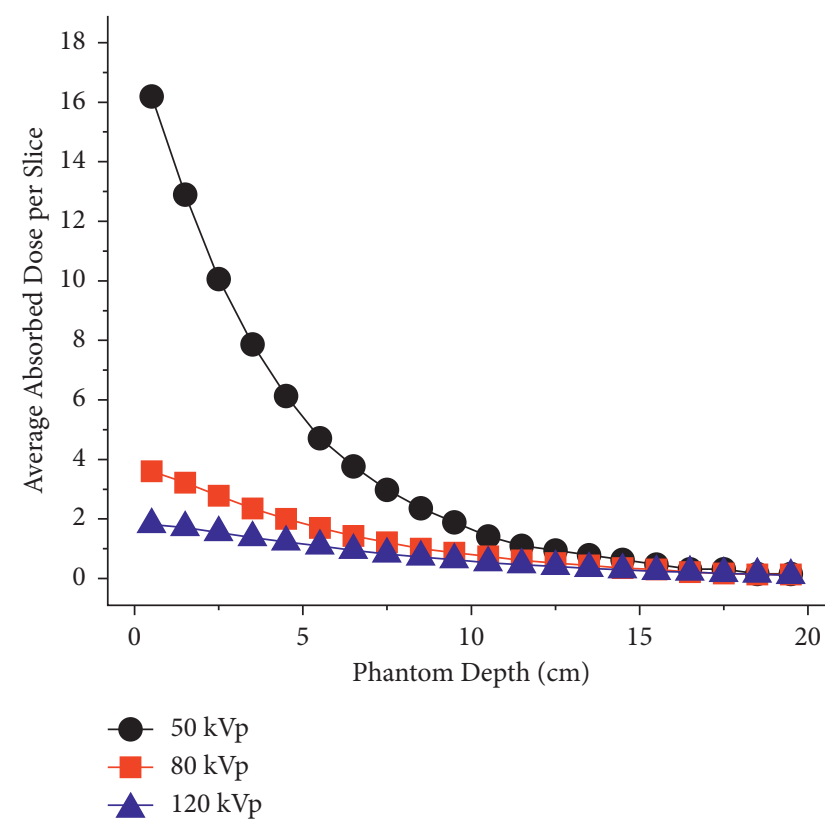

(a)

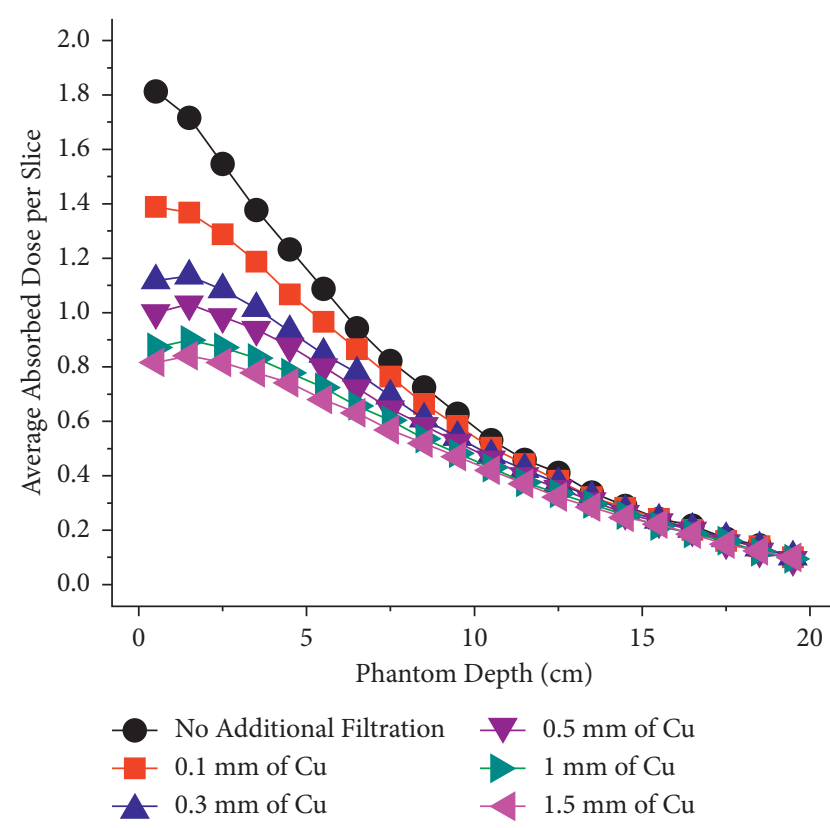

(b)

FIGURE 12: Depth absorbed dose profiles. Using Monte Carlo, the depth absorbed dose profiles were predicted for scans carried out (a) at 50, 80 , and $120 \mathrm{kVp}$ without additional filtration and (b) at $120 \mathrm{kVp}$ with copper filters with thicknesses between 0.1 and $1.5 \mathrm{~mm}$. The phantom was simulated as a $30 \times 30 \times 20 \mathrm{~cm}^{3}$ Solid Water ${ }^{\circledR}$ cuboid. The current was adjusted to simulate $8.5 \times 10^{5}$ photons transmitted out of the phantom (i.e., reaching the detector).

TABLE 5: Relative average absorbed dose.

\begin{tabular}{lcccc}
\hline $\begin{array}{l}\text { X-ray tube potential } \\
(\mathrm{kVp})\end{array}$ & $\begin{array}{c}\text { Amount of additional filtration }(\mathrm{mm} \text { of } \\
\mathrm{Cu})\end{array}$ & $\begin{array}{c}\text { Mean energy } \\
(\mathrm{keV})\end{array}$ & $\begin{array}{c}\text { Relative } \\
\text { current }\end{array}$ & $\begin{array}{c}\text { Relative average absorbed } \\
\text { dose }\end{array}$ \\
\hline 50 & 0 & 31.8 & 10.2 & 7.0 \\
80 & 0 & 42.4 & 2.8 & 2.2 \\
120 & 0 & 53.7 & 1.6 & 1.4 \\
120 & 0.1 & 59.0 & 1.3 & 1.2 \\
120 & 0.3 & 64.9 & 1.1 & 1.1 \\
120 & 0.5 & 68.1 & 1.0 & \\
120 & 1 & 74.1 & 0.9 & 0.9 \\
120 & 1.5 & 78.4 & 0.8 & 0.9 \\
\hline
\end{tabular}

Using Monte Carlo, the average absorbed dose in a $30 \times 30 \times 20 \mathrm{~cm}^{3}$ Solid Water ${ }^{\circledR}$ cuboid was calculated at 50,80 , and $120 \mathrm{kVp}$. The effect of the addition of copper filters with thicknesses between 0.1 and $1.5 \mathrm{~mm}$ was also investigated. The average absorbed dose was considered to be 1 at $120 \mathrm{kVp}$ in the presence of a $0.5 \mathrm{~mm}$ thick copper filter. The table also shows the mean energy of the X-ray beam incident on the phantom, which is similar to the experimental values within $10 \%$. The relative current is the scaling factor utilized to equalize the number of photons in the transmitted X-ray beam, which was set to $8.5 \times 10^{5}$ (i.e., the number of photons produced at $120 \mathrm{kVp}$ in the presence of a $0.5 \mathrm{~mm}$ thick copper filter).

values across the coatings using Image-Pro Plus 7 (Media Cybernetics, Rockville, USA), an image analysis software. A circle was drawn inside the coatings of both catheters in the $\mu \mathrm{CT}$ axial images shown in Figures 14(b) and 14(d). The intensities of all the pixels in the circles were then calculated in grey values. This analysis was also performed in uncoated sections of the catheters.

The variation in the pixel intensities of the coatings is shown graphically in Figure 15(a) for the vascular catheter and Figure 15(e) for the PTCA dilatation catheter. Figure 15 also shows $3 \mathrm{D}$ plots of the distribution of grey values in the coatings, generated with the same software. The mean pixel intensities calculated for the coatings are reported in Table 6 . For the vascular catheter, there is a $142 \%$ increase in pixel intensity when the catheter is coated with the rhenium-doped polymer-based coating (calculated relative to the pixel intensity of an uncoated section of the catheter). For the PTCA dilatation catheter, there is a $109 \%$ increase in pixel intensity (calculated relative to the pixel intensity of the balloon, without a coating). Furthermore, the standard deviations fall within $10 \%$ of the mean values, thus suggesting there is minimal variation in the pixel intensities of the coatings. 


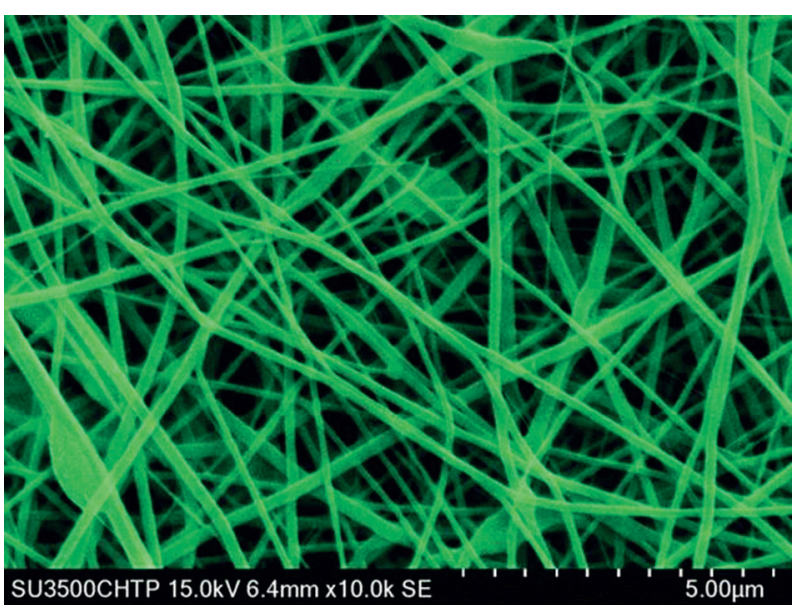

(a)

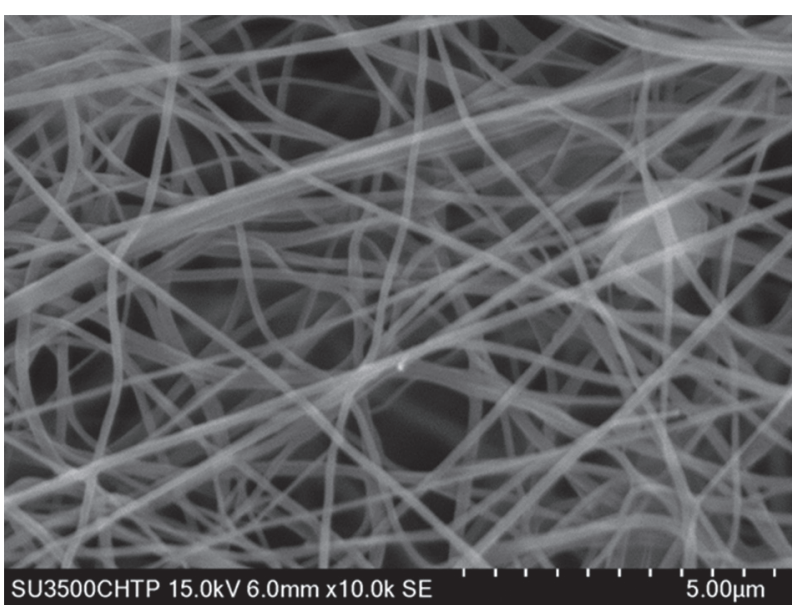

(b)

FIGURE 13: Morphology inspection of rhenium-doped and rhenium-free scaffolds. Images acquired by SEM are shown for (a) the rheniumdoped scaffold and (b) the rhenium-free scaffold. A pseudocolor was assigned to (a) to reflect the tint observed in the rhenium-doped scaffold.

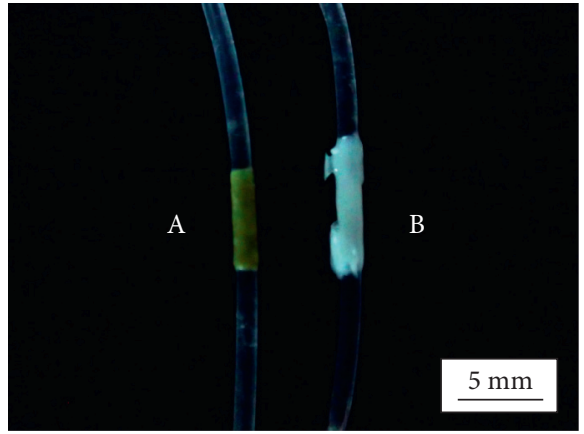

(a)

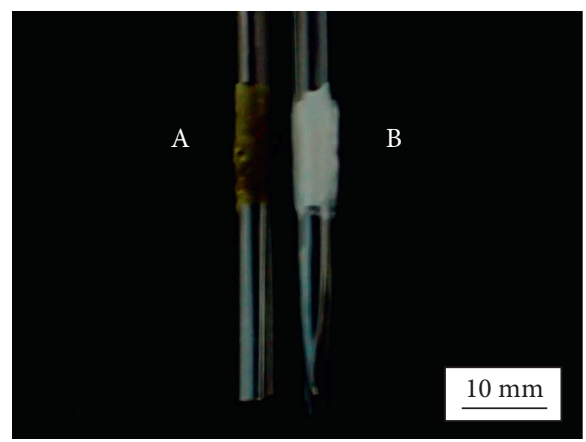

(c)

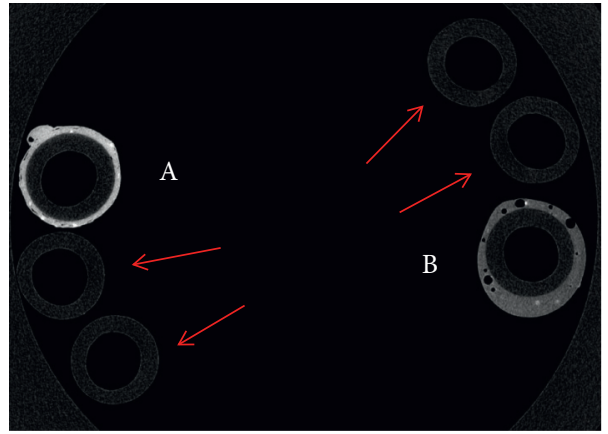

(b)

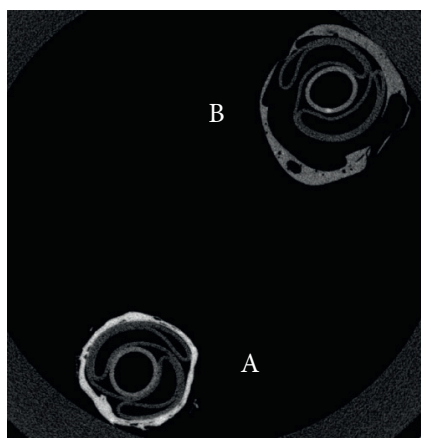

(d)

FIgURE 14: X-ray imaging of coated catheters. The images show $(a, b)$ the vascular catheters and $(c, d)$ the PTCA dilatation catheters coated with samples of (A) the rhenium-doped scaffold and (B) the rhenium-free scaffold. (b, d) Representative axial images acquired at $90 \mathrm{kVp}$ $(110 \mu \mathrm{As})$. (b) The catheters in (a). (d) The catheters in (c). A significant improvement, in contrast, is observed with the rhenium-doped polymer-based coating. Four uncoated catheters are included in (b) (indicated with red arrows). 


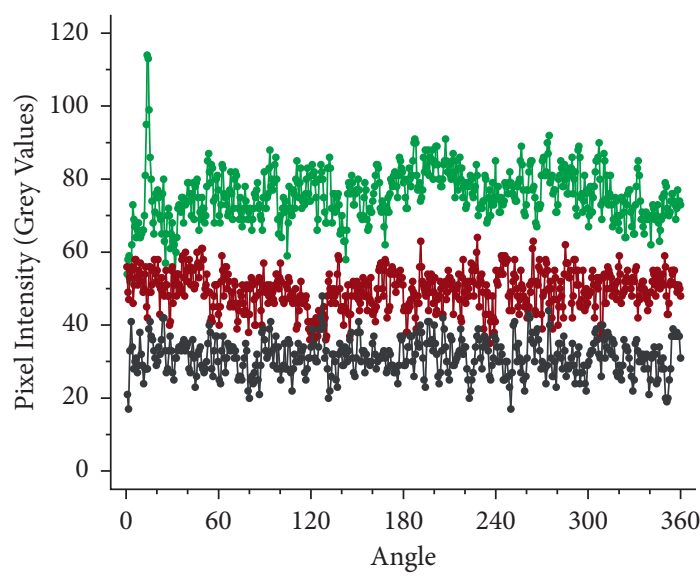

$\rightarrow$ Rhenium-Doped Polymer-Based Coating

$\rightarrow$ Rhenium-Free Polymer-Based Coating

$\rightarrow$ No Coating

(a)

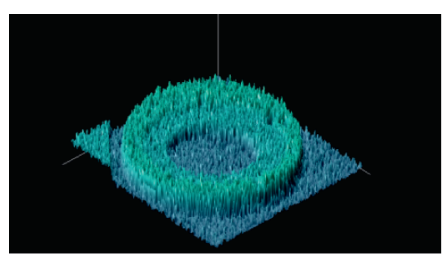

(c)

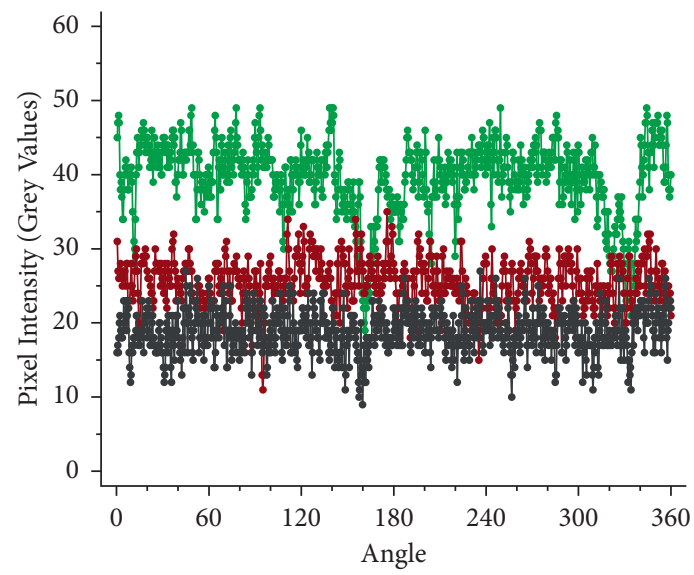

$\rightarrow$ Rhenium-Doped Polymer-Based Coating

- Rhenium-Free Polymer-Based Coating

- No Coating

(e)

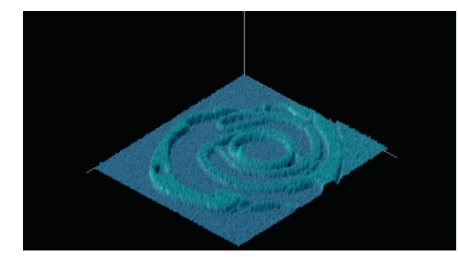

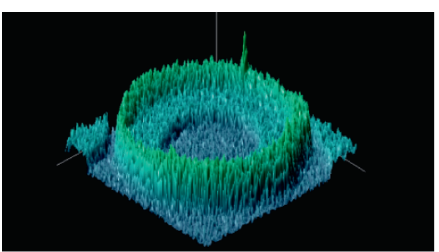

(b)

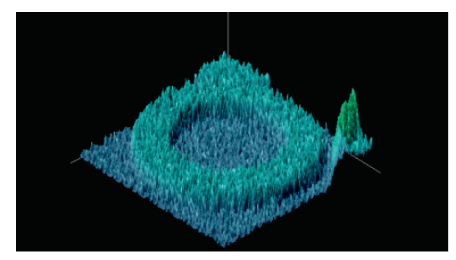

(d)

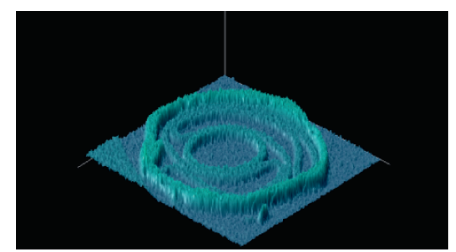

(f)

(g)

Figure 15: Pixel intensity analysis of the coatings. The pixel intensities were determined by measuring the grey values across circles drawn inside the coatings using Image-Pro Plus 7 (Media Cybernetics, Rockville, USA). The variation in pixel intensity across the coatings is shown in (a) for the vascular catheter and (e) for the PTCA dilatation catheter. 3D plots of the distribution of grey values are shown for the vascular catheter in (b), (c), and (d) and for the PTCA dilatation catheter in (f) and (g). Samples: (b, f) rhenium-doped polymer-based coating, (c, g) rhenium-free polymer-based coating, and (d) no coating. 
TABLE 6: Mean pixel intensity of the coatings.

\begin{tabular}{lcc}
\hline Structure & & Mean pixel intensity \\
& Vascular catheter & PTCA dilatation catheter \\
\hline Rhenium-doped polymer-based coating & $75.5+7.1$ & $39.5+5.0$ \\
Rhenium-free polymer-based coating & $49.5+5.2$ & $25.4+3.2$ \\
No coating & $31.3+5.0$ & $18.9+2.3$ \\
\hline
\end{tabular}

The mean pixel intensity of each structure was calculated by taking the average of all the grey values (see Figure 15). For the uncoated sections, the analysis was performed on the plastic for the vascular catheter and the balloon for the PTCA dilatation catheter.

\section{Conclusion}

This study provided further evidence that rhenium exhibits a $\mathrm{kVp}$-dependent superiority in CNR and attenuation over iodine. While there is typically a trade-off between absorbed dose and image quality, we showed that the absorbed dose is lower in scans where the CNR of rhenium is higher than that of iodine (specifically in scans over $120 \mathrm{kVp}$ with the use of filtration). High $\mathrm{kVp} \mathrm{X}$-rays are commonly used for imaging average-sized and large patients, but noisy images are often acquired due to the suboptimal X-ray attenuation of iodine. The utilization of rhenium in high $\mathrm{kVp} \mathrm{X}$-rays has the potential of enhancing contrast while minimizing absorbed dose.

We also showed that rhenium-doped electrospun scaffolds can be used to coat catheters, thus making them truly radiopaque. Making catheters radiopaque may allow physicians to place them inside the body more rapidly and precisely, potentially even with minimal or without the administration of I-XCA. This may also have applications to enhance contrast in guidewires and micro-guidewires used in pediatric applications.

Future work revolves around the development of novel, biodegradable Re-XCA and investigation of their in vitro and in vivo toxicity, as well as their biodistribution. For instance, rhenium-doped microspheres and NP have the potential of replacing clinically used I-XCA, thus increasing the contrast and the blood circulation time.

\section{Data Availability}

The data used to support the findings of this study are available from the corresponding author upon request.

\section{Disclosure}

A significant part of this manuscript formed chapters 2 and 3 of Dr. J. C. De La Vega's Ph.D. thesis. The thesis is available at https://open.library.ubc.ca/soa/cIRcle/collections/ubctheses/ 24/items/1.0354674.

\section{Conflicts of Interest}

The authors declare that they have no conflicts of interest.

\section{Acknowledgments}

This research was supported by a Collaborative Health Research Projects Grant from the Natural Sciences and Engineering Research Council (NSERC) in Canada and the
Canadian Institutes of Health Research (CIHR) as well as a Discovery Grant from NSERC to Dr. U. O. Häfeli. Dr. J. C. De La Vega acknowledges the National Council of Science and Technology (CONACYT) of Mexico for financial support through a 4-year Ph.D. scholarship.

\section{References}

[1] M. S. Levine, S. E. Rubesin, and I. Laufer, "Barium studies in modern radiology: do they have a role?" Radiology, vol. 250, no. 1, pp. 18-22, 2009.

[2] J. C. De La Vega and U. O. Häfeli, "Utilization of nanoparticles as X-ray contrast agents for diagnostic imaging applications," Contrast Media and Molecular Imaging, vol. 10, no. 2, pp. 81-95, 2015.

[3] L. M. Ho, R. C. Nelson, and D. M. DeLong, "Determining contrast medium dose and rate on basis of lean body weight: does this strategy improve patient-to-patient uniformity of hepatic enhancement during multi-detector row CT?" $R a$ diology, vol. 243, no. 2, pp. 431-437, 2007.

[4] GE Healthcare Inc, Omnipaque ${ }^{\mathrm{TM}}$ (Iohexol) Injection, p. 8, GE Healthcare Inc, Princeton, NJ, USA, 2010.

[5] Y.-N. Pan, A.-J. Li, X.-M. Chen, J. Wang, D.-W. Ren, and Q.-L. Huang, "Coronary computed tomographic angiography at low concentration of contrast agent and low tube voltage in patients with obesity:" Academic Radiology, vol. 23, no. 4, pp. $438-445,2016$.

[6] S. Y. Lee, C. M. Rhee, A. M. Leung, L. E. Braverman, G. A. Brent, and E. N. Pearce, "A review: radiographic iodinated contrast media-induced thyroid dysfunction," Journal of Clinical Endocrinology \& Metabolism, vol. 100, no. 2, pp. 376-383, 2015.

[7] W. Bottinor, P. Polkampally, and I. Jovin, "Adverse reactions to iodinated contrast media," International Journal of Angiology : Official Publication of the International College of Angiology, Inc, vol. 22, no. 3, pp. 149-154, 2013.

[8] M. Andreucci, R. Solomon, and A. Tasanarong, "Side effects of radiographic contrast media: pathogenesis, risk factors, and prevention," BioMed Research International, vol. 2014, Article ID 741018, 20 pages, 2014.

[9] C. B. Lightfoot, R. J. Abraham, T. Mammen, M. Abdolell, S. Kapur, and R. J. Abraham, "Survey of radiologists" knowledge regarding the management of severe contrast material-induced allergic reactions," Radiology, vol. 251, no. 3, pp. 691-696, 2009.

[10] R. S. Pumphrey, "Lessons for management of anaphylaxis from a study of fatal reactions," Clinical and Experimental Allergy, vol. 30, no. 8, pp. 1144-1150, 2000.

[11] F. M. Khan, The Physics of Radiation Therapy, Lippincott Williams \& Wilkins, Philadelphia, PA, USA, 2 edition, 1994.

[12] D. Marin, R. C. Nelson, G. D. Rubin, and S. T. Schindera, "Body CT: technical advances for improving safety," American Journal of Roentgenology, vol. 197, no. 1, pp. 33-41, 2011. 
[13] Y. Nakayama, K. Awai, Y. Funama et al., "Lower tube voltage reduces contrast material and radiation doses on 16-MDCT aortography," American Journal of Roentgenology, vol. 187, no. 5, pp. W490-W497, 2006.

[14] A. Fouras, M. J. Kitchen, S. Dubsky, R. A. Lewis, S. B. Hooper, and K. Hourigan, "The past, present, and future of $\mathrm{x}$-ray technology for in vivo imaging of function and form," Journal of Applied Physics, vol. 105, no. 10, Article ID 102009, 2009.

[15] W. Huda, K. A. Lieberman, J. Chang, and M. L. Roskopf, "Patient size and X-ray technique factors in head computed tomography examinations. I. Radiation doses," Medical Physics, vol. 31, no. 3, pp. 588-594, 2004.

[16] W. Huda, K. A. Lieberman, J. Chang, and M. L. Roskopf, "Patient size and X-ray technique factors in head computed tomography examinations. II. Image quality," Medical Physics, vol. 31, no. 3, pp. 595-601, 2004.

[17] K. Ogden, W. Huda, E. M. Scalzetti, and M. L. Roskopf, "Patient size and X-ray transmission in body CT," Health Physics, vol. 86, no. 4, pp. 397-405, 2004.

[18] R. Cheheltani, R. M. Ezzibdeh, P. Chhour et al., "Tunable, biodegradable gold nanoparticles as contrast agents for computed tomography and photoacoustic imaging," Biomaterials, vol. 102, pp. 87-97, 2016.

[19] P. C. Naha, K. C. Lau, J. C. Hsu et al., "Gold silver alloy nanoparticles (GSAN): an imaging probe for breast cancer screening with dual-energy mammography or computed tomography," Nanoscale, vol. 8, no. 28, pp. 13740-13754, 2016.

[20] P. A. Jackson, W. N. W. A. Rahman, C. J. Wong, T. Ackerly, and M. Geso, "Potential dependent superiority of gold nanoparticles in comparison to iodinated contrast agents," European Journal of Radiology, vol. 75, no. 1, pp. 104-109, 2010.

[21] J. F. Hainfeld, D. N. Slatkin, T. M. Focella, and H. M. Smilowitz, "Gold nanoparticles: a new X-ray contrast agent," British Journal of Radiology, vol. 79, no. 939, pp. 248-253, 2006.

[22] D. Tsvirkun, Y. Ben-Nun, E. Merquiol et al., "CT imaging of enzymatic activity in cancer using covalent probes reveal a size-dependent pattern," Journal of the American Chemical Society, vol. 140, no. 38, pp. 12010-12020, 2018.

[23] K. Ai, Y. Liu, J. Liu, Q. Yuan, Y. He, and L. Lu, "Large-scale synthesis of $\mathrm{Bi}_{2} \mathrm{~S}_{3}$ Nanodots as a contrast agent for in vivo $\mathrm{X}$-ray computed tomography imaging," Advanced Materials, vol. 23, no. 42, pp. 4886-4891, 2011.

[24] O. Rabin, J. Manuel Perez, J. Grimm, G. Wojtkiewicz, and R. Weissleder, "An X-ray computed tomography imaging agent based on long-circulating bismuth sulphide nanoparticles," Nature Materials, vol. 5, no. 2, pp. 118-122, 2006.

[25] P. J. Bonitatibus, A. S. Torres, G. D. Goddard, P. F. FitzGerald, and A. M. Kulkarni, "Synthesis, characterization, and computed tomography imaging of a tantalum oxide nanoparticle imaging agent," Chemical Communications, vol. 46, no. 47, pp. 8956-8958, 2010.

[26] P. J. Bonitatibus, A. S. Torres, B. Kandapallil et al., "Preclinical assessment of a zwitterionic tantalum oxide nanoparticle X-ray contrast agent," ACS Nano, vol. 6, no. 8, pp. 6650-6658, 2012.

[27] D. P. Cormode, P. C. Naha, and Z. A. Fayad, "Nanoparticle contrast agents for computed tomography: a focus on micelles," Contrast Media and Molecular Imaging, vol. 9, no. 1, pp. 37-52, 2014.

[28] E. E. Connor, J. Mwamuka, A. Gole, C. J. Murphy, and M. D. Wyatt, "Gold nanoparticles are taken up by human cells but do not cause acute cytotoxicity," Small, vol. 1, no. 3, pp. 325-327, 2005.

[29] P. C. Naha, P. Chhour, and D. P. Cormode, "Systematic in vitro toxicological screening of gold nanoparticles designed for nanomedicine applications," Toxicology in Vitro, vol. 29, no. 7, pp. 1445-1453, 2015.

[30] E. C. Dreaden, A. M. Alkilany, X. Huang, C. J. Murphy, and M. A. El-Sayed, "The golden age: gold nanoparticles for biomedicine," Chemical Society Reviews, vol. 41, no. 7, pp. 2740-2779, 2012.

[31] F. Kim, S. Connor, H. Song, T. Kuykendall, and P. Yang, "Platonic gold nanocrystals," Angewandte Chemie, vol. 116, no. 28, pp. 3759-3763, 2004.

[32] Y. Sun and Y. Xia, "Shape-controlled synthesis of gold and silver nanoparticles," Science, vol. 298, no. 5601, pp. 2176-2179, 2002.

[33] H. Sun, H. Li, I. Harvey, and P. J. Sadler, "Interactions of bismuth complexes with metallothionein(II)," Journal of Biological Chemistry, vol. 274, no. 41, pp. 29094-29101, 1999.

[34] A. L. Brown, P. C. Naha, V. Benavides-Montes, H. I. Litt, A. M. Goforth, and D. P. Cormode, "Synthesis, X-ray opacity, and biological compatibility of ultra-high payload elemental bismuth nanoparticle X-ray contrast agents," Chemistry of Materials, vol. 26, no. 7, pp. 2266-2274, 2014.

[35] A. L. Brown and A. M. Goforth, "Ph-dependent synthesis and stability of aqueous, elemental bismuth glyconanoparticle colloids: potentially biocompatible X-ray contrast agents," Chemistry of Materials, vol. 24, no. 9, pp. 1599-1605, 2012.

[36] J. A. Nadel, W. G. Wolfe, and P. D. Graf, "Powdered tantalum as a medium for bronchography in canine and human lungs," Investigative Radiology, vol. 3, no. 4, pp. 229-237, 1968.

[37] A. A. Krasilnikova, A. O. Solovieva, A. A. Ivanov et al., "A comparative study of hydrophilic phosphine hexanuclear rhenium cluster complexes' toxicity," Toxicology Research, vol. 6, no. 4, pp. 554-560, 2017.

[38] A. A. Krasilnikova, A. O. Solovieva, A. A. Ivanov et al., "Comprehensive study of hexarhenium cluster complex $\mathrm{Na}_{4}\left[\left\{\operatorname{Re}_{6} \mathrm{Te}_{8}\right\}(\mathrm{CN})_{6}\right]$ - in terms of a new promising luminescent and X-ray contrast agent," Nanomedicine: Nanotechnology, Biology and Medicine, vol. 13, no. 2, pp. 755-763, 2017.

[39] A. A. Krasilnikova, A. O. Solovieva, K. E. Trifonova et al., "Cellular internalization and morphological analysis after intravenous injection of a highly hydrophilic octahedral rhenium cluster complex-a new promising X-ray contrast agent," Contrast Media and Molecular Imaging, vol. 11, no. 6, pp. 459-466, 2016.

[40] A. A. Krasilnikova, M. A. Shestopalov, K. A. Brylev et al., "Prospects of molybdenum and rhenium octahedral cluster complexes as X-ray contrast agents," Journal of Inorganic Biochemistry, vol. 144, pp. 13-17, 2015.

[41] U. S. Geological Survey (USGS), Mineral Commodity Summaries 2020, U S Geological Survey, USA, 2020, https://doi. org/10.3133/mcs2020.

[42] A. Vogler and H. Kunkely, "Excited state properties of organometallic compounds of rhenium in high and low oxidation states," Coordination Chemistry Reviews, vol. 200-202, pp. 991-1008, 2000.

[43] J. R. Dilworth and S. J. Parrott, "The biomedical chemistry of technetium and rhenium," Chemical Society Reviews, vol. 27, no. 1, pp. 43-55, 1998.

[44] S. Abedi, "Therapeutic applications and dosimetry of radiopharmaceuticals with the help of compartmental analysis," in World Congress on Medical Physics and Biomedical 
Engineering, D. A. Jaffray, Ed., Springer International Publishing, Cham, Switzerland, pp. 674-678, 2015.

[45] J. Kutzner, M. Becker, and W. Grimm, "Zur osteotropie von rhenium- und yttrium-komplexen," Nuklearmedizin, vol. 22, pp. 162-165, 1983.

[46] P. W. Durbin, "Metabolic characteristics within a chemical family," Health Physics, vol. 2, pp. 225-238, 1960.

[47] U. O. Häfeli, S. Casillas, D. W. Dietz et al., "Hepatic tumor radioembolization in a rat model using radioactive rhenium $\left({ }^{186} \mathrm{Re} /{ }^{188} \mathrm{Re}\right)$ glass microspheres," International Journal of Radiation Oncology, Biology, Physics, vol. 44, no. 1, pp. 189199, 1999.

[48] S. Stolte, H. T. T. Bui, S. Steudte et al., "Preliminary toxicity and ecotoxicity assessment of methyltrioxorhenium and its derivatives," Green Chemistry, vol. 17, no. 2, pp. 1136-1144, 2015.

[49] T. J. Haley and F. D. Cartwright, "Pharmacology and toxicology of potassium perrhenate and rhenium trichloride," Journal of Pharmaceutical Sciences, vol. 57, no. 2, pp. 321-323, 1968.

[50] L. Y. Du, J. Umoh, H. N. Nikolov, S. I. Pollmann, T.-Y. Lee, and D. W. Holdsworth, "A quality assurance phantom for the performance evaluation of volumetric micro-ct systems," Physics in Medicine and Biology, vol. 52, no. 23, pp. 70877108, 2007.

[51] J. M. Boone and J. A. Seibert, "An accurate method for computer-generating tungsten anode X-ray spectra from 30 to 140 kV," Medical Physics, vol. 24, no. 11, pp. 1661-1670, 1997.

[52] J. H. Siewerdsen, A. M. Waese, D. J. Moseley, S. Richard, and D. A. Jaffray, "Spektr: a computational tool for X-ray spectral analysis and imaging system optimization," Medical Physics, vol. 31, no. 11, pp. 3057-3067, 2004.

[53] W. Huda and R. B. Abrahams, "Radiographic techniques, contrast, and noise in X-ray imaging," American Journal of Roentgenology, vol. 204, no. 2, pp. W126-W131, 2015.

[54] C. A. Schneider, W. S. Rasband, and K. W. Eliceiri, "NIH image to ImageJ: 25 Years of image analysis," Nature Methods, vol. 9, no. 7, pp. 671-675, 2012.

[55] S. Jan, D. Benoit, E. Becheva et al., "Gate V6: a major enhancement of the gate simulation Platform enabling modelling of CT and radiotherapy," Physics in Medicine and Biology, vol. 56, no. 4, pp. 881-901, 2011.

[56] M. S. Kovacs, P. Hein, S. Sattarzadeh, B. O. Patrick, T. J. Emge, and C. Orvig, "Complexes of phosphine-phenolate ligands with the $[\mathrm{Re}=\mathrm{O}]^{3+}$ and $\left[\mathrm{Re}\left(\mathrm{HNNC}_{5} \mathrm{H}_{4} \mathrm{~N}\right)\left(\mathrm{NNC}_{5} \mathrm{H}_{4} \mathrm{~N}\right)\right]^{2+}$ cores," Journal of the Chemical Society, Dalton Transactions, no. 20, pp. 3015-3024, 2001.

[57] A. Parsa, N. Ibrahim, B. Hassan, A. Motroni, P. F. van der Stelt, and D. Wismeijer, "Reliability of voxel gray values in cone beam computed tomography for preoperative implant planning assessment," The International Journal of Oral \& Maxillofacial Implants, vol. 27, no. 6, pp. 1438-1442, 2012.

[58] J. V. Valiyaparambil, I. Yamany, D. Ortiz et al., "Bone quality evaluation: comparison of cone beam computed tomography and subjective surgical assessment," The International Journal of Oral \& Maxillofacial Implants, vol. 27, no. 5, pp. 1271-1277, 2012.

[59] Y. Nomura, H. Watanabe, E. Honda, and T. Kurabayashi, "Reliability of voxel values from cone-beam computed tomography for dental use in evaluating bone mineral density," Clinical Oral Implants Research, vol. 21, no. 5, pp. 558-562, 2010.
[60] P. Mah, T. E. Reeves, and W. D. McDavid, "Deriving Hounsfield units using grey levels in cone beam computed tomography," Dentomaxillofacial Radiology, vol. 39, no. 6, pp. 323-335, 2010.

[61] X.-ray transition energy: K-edge table; http://physics.nist.gov/ cgi-bin/XrayTrans/search.pl?download=column\&element= All\&trans $=$ Kedge\&lower $=8000$ \&upper $=200000$ \&units $=e V$.

[62] B. Nilsson and A. Brahme, "Relation between kerma and absorbed dose in photon beams," Acta Radiologica-Oncology, vol. 22, no. 1, pp. 77-85, 1983. 